\title{
Physiotherapists' perceptions of collaborations with inter-professional team members in an ICU setting
}

\author{
M N Ntinga, MSc; OrcID 0000-0002-9725-9312; H van Aswegen, PhD; OrcID 0000-0003-1926-4690 \\ Department of Physiotherapy, Faculty of Health Sciences, University of the Witwatersrand, Johannesburg, South Africa \\ Corresponding author: M N Ntinga (nomusa.ntinga@uct.ac.za)
}

\begin{abstract}
Background. In the intensive care unit (ICU) environment, inter-professional team collaborations have direct impact on patient care outcomes. Current evidence shows that providing physiotherapy to ICU patients shortens their length of stay and reduces their incidence of ventilator associated pneumonia and severity of critical illness neuropathy. Physiotherapists' perceptions of their interactions with nurses and doctors as inter-professional team members in the ICU is important.

Objectives. To identify barriers and enablers of physiotherapists' interactions with inter-professional team members in adult ICU settings, identify solutions to the barriers and determine if perceptions of interactions with ICU team members differ between junior and senior physiotherapists. Methods. A qualitative study was done using semi-structured group discussions. Participants were recruited using convenience sampling. Participants were junior and senior physiotherapists from four private and four public sector hospitals in urban Johannesburg, South Africa. Interviews were audio recorded. Recordings were transcribed and direct content analysis of data was done to create categories, subcategories and themes.

Results. Twenty-two junior and 17 senior ICU physiotherapists participated in the study. Barriers raised by physiotherapists regarding communication with inter-professional team members in the ICU were non-ICU trained staff working in ICU, personality types, lack of professional etiquette, and frequent rotation of ICU staff. Enablers of communication with inter-professional team members were presence of team members in ICU during the day, good time management, teamwork approach to care and sharing of knowledge. Differing paradigms of teamwork among health professionals was highlighted as a cause of tension in the ICU inter-professional collaborations.

Conclusion. Physiotherapists are important members of the inter-professional ICU team. Exploring their interactions with other team members identified solutions that may improve collaboration between inter-professional team members to facilitate improved patient outcomes. Inter-professional education should inform ICU policies to create an environment that fosters teamwork. Finding creative ways to adequately staff the ICU without losing quality or driving up costs of care are matters that should take priority among policy makers.

Keywords. critical care; physiotherapy; communication; inter-professional teams; perceptions; patient care.
\end{abstract}

South Afr J Crit Care 2020;36(2):86-91. https://doi.org/10.7196/SAJCC.2020.v36i2.431

Contribution of the study. Physiotherapists are essential and strategically placed in the ICU to reduce length of stay, and prevent patient physical function decline post ICU admission. This work explored physiotherapists' perceptions of collaboration within inter-professional teams in the ICU and identified barriers that impede communication in inter-professional teams and suggested solutions. This research will contribute in improving collaboration between inter-professional teams in the ICU setting.

The intensive care unit (ICU) is an ideal environment for interprofessional collaborations to take place, because of the high turnover of critically ill patients, new technological advances and being a specialised area of healthcare. ${ }^{[1]}$ Inter-professional team collaboration allows enhanced patient safety, better use of resources by avoiding duplication of treatment and improved standards of patient care as the time and skills of the professionals are efficiently utilised. ${ }^{[2]}$ Nurses spend the most time with ICU patients during their 12-hour shifts and are the major communicators in the inter-professional ICU team. They are responsible for relaying messages between different team members and facilitating communication between patients and their family members. ${ }^{[3]}$ Physiotherapists are integral members of the inter-professional team that care for critically ill patients. Moderateto-high quality evidence exists to show that physiotherapy-driven interventions such as early mobilisation of ICU patients, application of exercise therapy, respiratory therapy techniques, and their involvement with patient weaning and extubation from mechanical ventilation (MV) is associated with reduced rates of ventilatoracquired pneumonia, duration of MV, length of stay (LOS) in the hospital, improved respiratory and peripheral muscle strength, patient participation in activities of daily living and functional activities, and improved exercise capacity at hospital discharge. ${ }^{[4,5,6]}$ Teamwork between ICU staff is essential to ensure that patients reap the benefits of out-of-bed mobilisation, inter-professional team-driven weaning protocols to enhance their liberation from MV and other rehabilitation interventions. ${ }^{[6,7]}$

Limiting hierarchical structures in patient care is important to empower the respective inter-professional team members to use their clinical reasoning skills and have the confidence to carry out their autonomy in patient care. ${ }^{[8]}$ The TEAM study showed that acquiring skills in team building and continuing professional development (CPD) improved teamwork dynamics in the ICU. ${ }^{[9]}$ The presence of nursing leaders in 
an ICU setting who address matters of staff motivation, education, skills building, team building and play a role in facilitating interactive supervision, improved inter-professional teamwork dynamics. ${ }^{[10,11]}$

Healthcare facilities that employ highly qualified healthcare professionals report improved patient outcomes and positive patient feedback of their hospital stay. ${ }^{[12]}$ In neonatal ICU care, communication failures among inter-professional team members as opposed to individual errors accounted for up to $72 \%$ of causes of perinatal death and injury. ${ }^{[13]}$ Patients in ICU are critically ill and require differing levels of care and expertise in their management. There is a high turnover of nursing staff working in ICU as many feel that they are unable to cope with patient demands or that they are inadequately trained for effective management of critically ill patients. ${ }^{[14]}$ It was highlighted that when a written common goal-orientated tool sheet was used during ICU ward rounds to document and illustrate information of patient treatment goals and patient response to treatment, cohesion and collaboration among health professionals in ICU was greatly improved. ${ }^{[15]}$

Exploration of dynamics within the inter-professional ICU team is important to identify enablers and barriers that may impact interaction of physiotherapists with the team. Interventions to address barriers can be developed and tested to enhance relations between inter-professional ICU team members to optimise patient care. ${ }^{[14-16]}$ There are currently no reports available in South Africa that explore collaboration, interactions and communication between physiotherapists and other interprofessional ICU team members. This study was conducted to establish physiotherapists' perceptions of interactions with the inter-professional team members in private- and public-sector adult ICU settings.

\section{Methods Study Design}

A qualitative study design was carried out using semi-structured group discussions which were facilitated by stimulus questions. Discussions were audio-recorded.

\section{Participants}

The study population consisted of junior and senior physiotherapists who worked in adult ICU settings in Johannesburg. Junior physiotherapists who had been working in an adult ICU setting for $1-5$ years were approached for possible participation. Senior physiotherapists who had daily working experience in an adult ICU for 5 years or longer were approached for participation.

A convenience sampling method was used to recruit participants for this study. Interviews were held with physiotherapists from 4 public sector and 4 private sector hospitals.

\section{Procedure}

Permission to conduct this study was obtained from the University of the Witwatersrand Human Research Ethics (Medical) committee (ref. no. M140345). Physiotherapy private practice owners (whose practices serve adult ICUs in private hospitals) and heads of department of public sector hospitals (with adult ICUs) in Johannesburg were contacted and provided with information about the study purpose and aims. Junior and senior physiotherapists who agreed to participate were provided with dates and times that were convenient for their 1-hour semi-structured group discussion session. Group discussion sessions were held at a venue convenient for the participants. The participants were split into 13 groups. Senior and junior participants were interviewed separately. Each semi-structured group discussion session commenced with a brief introduction and explanation of the procedure, rules and what was expected from the participants. This was accompanied by distribution of the study information sheet, consent forms, and demographic and clinical information sheets which were completed by participants prior to initiation of the interview and discussions.

Thirteen semi-structured group discussion sessions were conducted in July and August 2014. Information was obtained by posing stimulus questions to each group. Handwritten notes were made during each group discussion session while the discussions were being recorded (Olympus VN-5500PC digital voice recorder; Olympus, USA). The recordings added to the credibility, applicability and transferability of the data collected. No participants declined audio recording. Data saturation occurred when all participants completed their group discussion sessions and no new information was forthcoming.

The recorded discussions were transcribed verbatim into written transcripts for data analysis. Data cleaning was done by listening to the tape recordings while reading the transcribed notes. After transcription, cross-referencing between recorded and written notes for each semistructured group discussion session was done to ensure accuracy of data obtained. The transcribed notes were sent to some of the participants for verification of its correctness. A directed content analysis approach was used to present the information obtained. This was done using an inductive approach because it was concerned with the generation of new theory emerging from the qualitative data, e.g. themes and codes which were generated by the stimulus questions. Trustworthiness of information obtained was ensured through adherence to strategies such as credibility (including member checking), transferability, dependability and confirmability.

Quantitative data obtained were summarised using descriptive statistics. Statistical analysis was performed using SPSS software version 24 (IBM Corp., USA) Continuous variables (age and years worked in ICU) were summarised as mean, minimum and maximum, and standard deviation (SD). Comparisons between junior and senior physiotherapists for age and years worked in ICU were made using an independent $t$-test. Categorical variables (e.g. gender, healthcare sector, etc.) were summarised as numbers and percentages.

\section{Results}

A total number of 39 physiotherapists participated in the semi-structured group discussions. The characteristics and working environment of the participants are summarised in Table 1. The mean (standard deviation (SD)) age of the total participants was 30.7 (8.73) years. The majority of participants were female $(92.3 \% ; n=36)$. Participants worked in more than one ICU at a time when the semi-structured group discussions sessions were held. There was an expected significant difference in age and ICU working experience between junior and senior participants. Most of the junior participants worked in the public healthcare sector. There was an equal distribution of senior participants in public and private sectors. Some participants had other qualifications that included a diploma in HIV medicine ( $n=1)$, diploma in animal sciences $(n=1)$ and diploma in equestrian anatomy $(n=1)$.

\section{Physiotherapists as members of the inter- professional ICU team}

All participants viewed themselves as an important part of the ICU inter-professional team. They felt that they provided an essential service to patients in ICU. The reasons why participants felt they were important team members are summarised in Table 2. This perception was substantiated by the level of satisfaction that nurses and patients expressed towards physiotherapy involvement with patient care. 
Table 1. Participant characteristics $(N=39)$

\begin{tabular}{|c|c|c|c|}
\hline Characteristics & $\begin{array}{l}\text { Junior physio- } \\
\text { therapists } \\
(n=22), n(\%)^{*}\end{array}$ & $\begin{array}{l}\text { Senior physio- } \\
\text { therapists } \\
(n=17), n(\%)^{*}\end{array}$ & $p$-value \\
\hline Age (years), mean (SD) & $24.45(1.54)$ & $38.76(7.43)$ & 0.00 \\
\hline \multicolumn{4}{|l|}{ Gender } \\
\hline Male & $1(4.55)$ & $2(11.76)$ & \\
\hline Female & $21(95.5)$ & $15(88.23)$ & \\
\hline \multicolumn{4}{|l|}{ Healthcare sector } \\
\hline Public & $14(63.64)$ & $9(52.94)$ & \\
\hline Private & $8(36.37)$ & $8(47.06)$ & \\
\hline $\begin{array}{l}\text { Years of experience in } \\
\text { ICU, mean (SD) }\end{array}$ & $2.36(1.26)$ & $12.76(6.77)$ & 0.00 \\
\hline \multicolumn{4}{|l|}{$\begin{array}{l}\text { Types of ICU in which } \\
\text { participants work }\end{array}$} \\
\hline Cardiac ICU only & $1(4.55)$ & $1(5.88)$ & \\
\hline General ICU only & $6(27.27)$ & $5(29.41)$ & \\
\hline Surgical ICU only & $0(0)$ & $1(5.88)$ & \\
\hline Trauma ICU only & $3(13.64)$ & $3(17.65)$ & \\
\hline $\begin{array}{l}\text { Cardiac and general } \\
\text { ICUs }\end{array}$ & $2(9.09)$ & $0(0)$ & \\
\hline $\begin{array}{l}\text { Surgical and trauma } \\
\text { ICUs }\end{array}$ & $1(4.54)$ & $0(0)$ & \\
\hline $\begin{array}{l}\text { Cardiac and trauma } \\
\text { ICUs }\end{array}$ & $1(4.54)$ & $0(0)$ & \\
\hline All ICUs & $8(36.36)$ & $7(41.17)$ & \\
\hline \multicolumn{4}{|l|}{$\begin{array}{l}\text { Postgraduate } \\
\text { qualifications }\end{array}$} \\
\hline $\begin{array}{l}\text { MSc Physiotherapy } \\
\text { (field of cardio- } \\
\text { pulmonary } \\
\text { physiotherapy) }\end{array}$ & 0 & $6(35.29)$ & \\
\hline $\mathrm{PhD}$ & 0 & $1(5.88)$ & \\
\hline Other & 0 & $3(17.65)$ & \\
\hline None & $22(100)$ & $7(41.17)$ & \\
\hline
\end{tabular}

\section{Physiotherapists' perceptions of interactions with inter-professional team members in ICU}

The inter-professional team members most reported on were nurses and doctors. Participants shared their feelings about their perceptions of interactions with inter-professional team members and several participants expressed that their attitudes depended on the professional they were interacting with (Table 3).

\section{Factors that influence communication with inter-professional team members in ICU}

Participants shared that several factors influenced their communication with other inter-professional ICU team members (Table 4).

\section{Factors that affect patient care in ICU}

A factor that enabled quality patient care in ICU was identified as having open lines of communication within the inter-professional team, and barriers were medical hierarchy and not having regular access to other healthcare professionals (Table 5).

\section{Solutions to identified barriers:}

Participants suggested several solutions to the perceived barriers encountered with inter-professional team members working in ICU (Table 6).
Table 2. Reasons why participants felt they were important team members:

\begin{tabular}{|c|c|}
\hline Codes & Quotes \\
\hline $\begin{array}{l}\text { Satisfaction with service } \\
\text { provision }\end{array}$ & $\begin{array}{l}\text { '...have the odd one or two patients that } \\
\text { actually come back and say thank you } \\
\text { and will actually thank you for - even } \\
\text { it's the smallest thing that you've done...' } \\
\text { [private sector participants]. }\end{array}$ \\
\hline $\begin{array}{l}\text { Clinical reasoning and } \\
\text { evidence-based practice }\end{array}$ & $\begin{array}{l}\text { '...often identify problems... when you } \\
\text { [are] working so intimately with the } \\
\text { patient, that problems may not have } \\
\text { been picked up earlier on.' [public sector } \\
\text { participant]. }\end{array}$ \\
\hline $\begin{array}{l}\text { Cost-savings for hospitals } \\
\text { by reducing length of stay }\end{array}$ & $\begin{array}{l}\text { '...quite honestly if we [physiotherapists] } \\
\text { weren't there, the patient would still be } \\
\text { in bed for } 24 \text { hours...' [private sector } \\
\text { participant]. }\end{array}$ \\
\hline Staff and patient education & $\begin{array}{l}\text { '...in our practice we...say '...we are coming } \\
\text { through, there is the power breather, let's } \\
\text { start using it. Let's try it and we [are] } \\
\text { committed to in service training, so we } \\
\text { want to be at the forefront... the early } \\
\text { mobility and they [nurses] won't do it } \\
\text { without us.' [private sector participant]. } \\
\text { AND } \\
\text { '...you [physiotherapist] take the x-ray and } \\
\text { you show them [patients] this is what's } \\
\text { broken, or this is what's wrong, or this } \\
\text { is what's wrong with your chest... this is } \\
\text { what our role is. So, they understand... } \\
\text { [public sector participants] }\end{array}$ \\
\hline
\end{tabular}

Table 3. Brief list of feelings experienced by participants while interacting with team members

\begin{tabular}{|c|c|}
\hline Codes & Quotes \\
\hline Positive feelings & $\begin{array}{l}\text { The junior participants expressed helpfulness } \\
\text { among the nursing staff: '... the nurses are } \\
\text { there, they want to help, and they ask you } \\
\text { for advice on how they can carry on with the } \\
\text { treatment throughout the day...' [private sector } \\
\text { participant]. }\end{array}$ \\
\hline Negative feelings & $\begin{array}{l}\text { A participant from the public sector shared: } \\
\text { '...there's a nice working relationship but you } \\
\text { get to some of them and if the nurse is not so } \\
\text { helpful then it makes it more difficult because } \\
\text { you can't just pull another nurse to come } \\
\text { because... they each have their own patient... } \\
\text { [public sector participant]. }\end{array}$ \\
\hline Mixed feelings & $\begin{array}{l}\text { Emotional influences were noted in the way } \\
\text { professionals treated each other such as moods } \\
\text { and bad attitude: } \\
\text { '...is usually more on a personality level. So, } \\
\text { if people just generally don't get along, that's } \\
\text { the only time you'll have something negative' } \\
\text { [private sector participant]. }\end{array}$ \\
\hline
\end{tabular}

The differences in responses between junior and senior participants showed that hierarchy and the lack of familiarity with team members, lack of knowledge of ICU equipment and ICU policies weighed heavily on the junior participants while the senior participants valued avoiding errors by mitigating fatigue, reducing high staff turnover, and opening lines of communication between team members. 


\begin{tabular}{|c|c|c|}
\hline & Codes & Quotes \\
\hline \multirow[t]{6}{*}{ Enablers } & Friendliness & '...they are easy to phone which is nice...' [private sector participant]. \\
\hline & Positive attitude & $\begin{array}{l}\text { '...it's also us saying we understand your point of view however we like to do this, where can we meet halfway?' } \\
\text { [private sector participant]. }\end{array}$ \\
\hline & $\begin{array}{l}\text { Presence in the } \\
\text { unit }\end{array}$ & $\begin{array}{l}\text { 'So, we [physiotherapists] are lucky, a lot of the [staff] we work with, have been around a long time and we work closely } \\
\text { with them, so they value our opinions and that's positive...' [private sector participant]. }\end{array}$ \\
\hline & Teamwork & $\begin{array}{l}\text { '...occupational therapists sometimes, they'll treat with us or sometimes...they'll wait for us to finish and then come } \\
\text { back and treat.' [public sector participant]. }\end{array}$ \\
\hline & Listening skills & $\begin{array}{l}\text { 'You know if you get to a nursing staff member and they say we can't mobilise this patient, I always say but why? And then } \\
\text { we will come to an agreement between their reasons for not doing it and my reasons for wanting to do it. So, it's not like } \\
\text { we are seen as this force that comes in and we do stuff and we walk out again' [private sector participant]. }\end{array}$ \\
\hline & $\begin{array}{l}\text { Mentoring of } \\
\text { junior staff }\end{array}$ & $\begin{array}{l}\text { 'You know if I'm not there then [my next in line] does it but basically, that involves for us to do rounds, check up all the } \\
\text { patients, allocate patients to physiotherapists so for me I know all the patients and I know what's going on with them so } \\
\text { that facilitates communication...' [private sector participant]. }\end{array}$ \\
\hline \multirow[t]{5}{*}{ Barriers } & $\begin{array}{l}\text { Hierarchical } \\
\text { structure in unit }\end{array}$ & '[Doctors]not approachable, yes it makes things quite difficult'[private sector participant]. \\
\hline & Staff rotation & '...it is more the locum nurses that don't quite know what to do in ICU'. [public sector participant] \\
\hline & $\begin{array}{l}\text { Staffing levels } \\
\text { in unit }\end{array}$ & $\begin{array}{l}\text { '... think with neuro-surgery hi-care, the nurses often complain about the fact that they are short staffed so it will be one } \\
\text { professional nurse and one auxiliary nurse that nurses four patient whereas in main ICU it is one nurse to one patient.' } \\
\text { [public sector participant]. }\end{array}$ \\
\hline & $\begin{array}{l}\text { Non-ICU } \\
\text { trained staff }\end{array}$ & $\begin{array}{l}\text { 'The patient was not even breathing. And she [the nurse] ...didn't quite know what to do and I actually had to get the unit } \\
\text { manager' [private sector participant] }\end{array}$ \\
\hline & $\begin{array}{l}\text { Personality } \\
\text { types }\end{array}$ & $\begin{array}{l}\text { 'Their moods and... their personalities can influence.... whether they [are] approachable or not. You know some...are much } \\
\text { more approachable than others... [private sector participant]. }\end{array}$ \\
\hline
\end{tabular}

ICU = intensive care unit.

Table 5. Factors that influence patient care in ICU

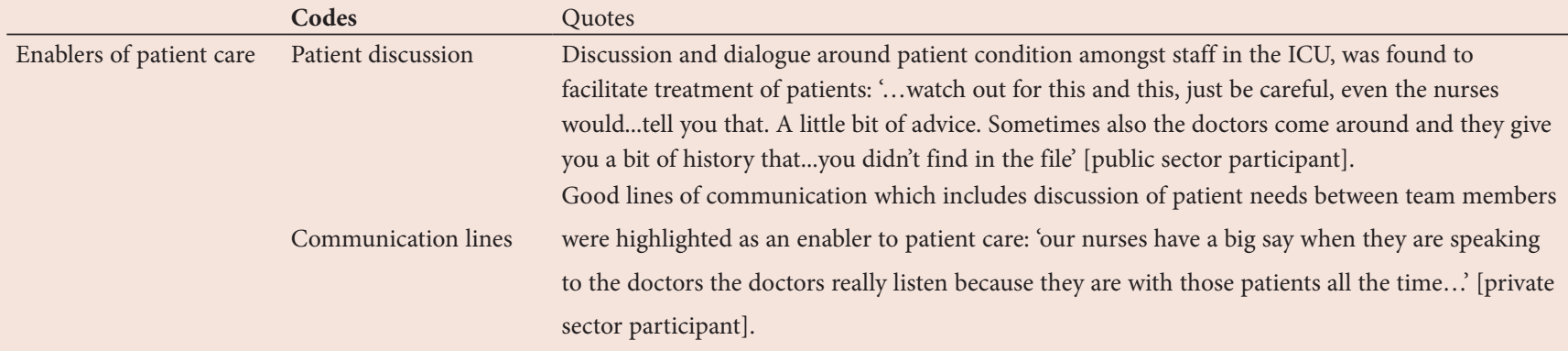

Time management

Optimal use of time in the unit was found to facilitate patient treatment: 'I think if the nurses are ready waiting for you and then you...go there and you...get it [treatment] done' [public sector participant].

Trust

Mutual trust between inter-professional team members where a physiotherapist displays a good work ethic leads to better relationships in the ICU: 'So instead of us just doing a five-minute chest treatment, stay a full length and do it for 20 minutes. I think they will appreciate us more...' [public-sector participant]

Positive attitude A helpful, positive attitude executed with confidence and professionalism amongst professionals in the ICU was seen as enabler: '...so I think it's important that in ICU with the consistency of people changing is that they should help each other instead of thinking... 'I don't know what to do but let me just carry on what I'm doing instead of asking'... [private-sector participant]

Orientation Orientation of new staff into the unit and building familiarity between professionals was viewed as an enabler '...someone told me...they'd take a picture [of the staff member] and save it on their phone with the picture and their name with their phone number, but you're using it to remember their name. That's what a friend of mine did... [public-sector participant]. 
Table 5. (continued) Factors that influence patient care in ICU

\begin{tabular}{|c|c|c|}
\hline & Codes & Quotes \\
\hline \multirow[t]{5}{*}{ Barriers of Patient Care } & Attitude & $\begin{array}{l}\text { An avoidant attitude by inter-professional team members was highlighted as a barrier: '.... the } \\
\text { moment they see the physio it is their time to go do something else instead of actually asking you } \\
\text { if you need help...' [public-sector participant]. }\end{array}$ \\
\hline & Hierarchy & $\begin{array}{l}\text { Hierarchical structure in units resulted in difficulty for physiotherapists to relate to some inter- } \\
\text { professional team members in the ICU: 'Doctors have the feeling of being like a hierarchy. The } \\
\text { specialists are harder to approach... [public-sector participant] }\end{array}$ \\
\hline & & $\begin{array}{l}\text { When physiotherapists have to follow instructions from hierarchical structures during treatment } \\
\text { this was reported to lead to interruptions in progression of patient management, thus hindering } \\
\text { patient-care: '...we [physiotherapists] need to take a backseat and stop what we are doing when } \\
\text { the doctors are there or when the nurses want to take blood or something... [private sector } \\
\text { participant], and : 'The doctors, I think they are a bit interruptive...' [public-sector participant]. }\end{array}$ \\
\hline & Fatigue & $\begin{array}{l}\text { It was suggested that staff fatigue could be avoided by increasing pay for nurses which would } \\
\text { affect the quality of patient-care rendered by reducing demand for overtime shifts to make } \\
\text { sufficient revenue: '...the only reason they [nurses] actually move out of there is because someone } \\
\text { else pays better or the hours are better, not because they want to stop nursing...' [private-sector } \\
\text { participant]. }\end{array}$ \\
\hline & Busyness & $\begin{array}{l}\text { When the ICU is very busy, doctors may miss additional patient-related injuries. The rapid } \\
\text { demand for ICU beds therefore hinders planning and execution of appropriate patient } \\
\text { management: 'We [physiotherapists] had a [patient with a] head injury and we totally missed that } \\
\text { the patient had a pelvic fracture and obviously it wasn't documented [by other team members] } \\
\text { anywhere in the file.' [public-sector participant]. }\end{array}$ \\
\hline
\end{tabular}

Table 6. Solutions for barriers encountered between inter-professional team members.

\begin{tabular}{l} 
Solution \\
\hline Implementation of patie \\
pathways \\
Structured treatment tim \\
Training of new staff \\
Inter-professional CPD \\
activities
\end{tabular}

Sharing ideas on patient care

Swift conflict resolution Quote

'...you the physio[therapist] are working in ICU, you [should] know the protocol and you should adhere to...it...' [public sector participant].

'...we [physiotherapists] would go in at exactly eight thirty and we [physiotherapists] would go in at exactly one o' clock to the ICU and maybe two of us would start there, and we[physiotherapists] would help [each other] clear the ICU patient load... [public sector participant].

'...if they [new nurses] are shadowing a specific nurse it makes it easier but maybe for that person to have a tick list to ensure everything has been covered [during orientation]. [public sector participant].

....and earlier in the year they [physiotherapists] did in-service training on mobilisation and how to be careful with your own back and how to mobilise patients and then I [physiotherapist] was in a car accident and I couldn't mobilise my patients but because all the nurses had just done in- service training it was...much easier and now they [nurses] are so much more professional at mobilizing because they know how to do it properly...' [public sector participant].

'It's also nice to share your knowledge because the different institutions teach different things. I mean...the basis is the same, but we all have different lecturers that share what you learn at Wits v. what you learn at Tuks v. what you learn at UKZN...I think...rather pool your knowledge...' [public sector participant].

'...if it's really like two people not seeing eye to eye, then I may not allocate a physio. In fact, we had an incident with a locum, who had a huge blow out with a sister and I just moved them... [private sector participant].

\section{Discussion}

Information obtained through the semi-structured group interviews revealed that physiotherapists felt valued as part of the inter-professional team that works in ICU. They raised several enablers and barriers that they experience in relation to communication among the interprofessional team members, which have an impact on the quality of patient care provided in this setting. Important barriers highlighted included lack of orientation programmes for new staff joining the ICU team and overworked healthcare professionals who are responsible for many patients, which may result in misdiagnosis and management errors. Some participants shared ideas to resolve identified barriers to enable better working relations among team members and to optimise patients' responses to care and their clinical outcomes.
There is evidence that young female healthcare professionals employed in ICU are chronically fatigued, frustrated and emotionally disengaged compared with other healthcare professionals due to high workload, poor sense of community, poor remuneration and little control over their work structure. ${ }^{[1,18]}$ Job satisfaction studies reported that when nursing leaders are present in the ICU and address matters of staff motivation, remuneration, education, skills/team building and play a role in facilitating interactive supervision, it improved the interprofessional teamwork dynamic. ${ }^{[19]}$ The frequent rotation of staff in and out of ICU cannot be curbed owing to remuneration deficits in the SA work sector and a rising demand for ICU beds. The implementation of strict ICU orientation policies and mentorship programmes for junior staff by pairing them with experienced and qualified critical care 
health professionals who will mentor, advise, guide and support them throughout their rotation in the ICU, could improve work dynamics among the inter-professional team members. Moreover, staff should be required to attend $\mathrm{CPD}$ courses specific to their professional role in an ICU setting. This would ensure a high standard of continuity of patient care in the ICUs.

Non-ICU-trained staff working in the ICU was raised as a barrier to inter-professional teamwork. Electronic ICU (e-ICUs/TELE-ICUs) has been suggested as a solution for addressing the lack of ICU-trained healthcare professionals in developed countries. These e-ICUs are a form of telemedicine, where healthcare professionals can access the ICUs remotely, provide expert care and advise to ICU practitioners while accessing patient information offsite and providing mentoring to less experienced or qualified healthcare professionals. ${ }^{[20]}$ Currently, this is not an option to ICU healthcare professionals in SA where virtual ICU centres would take away the physical presence of skilled staff, intensivists and resources from the severely ill patient's bedside. ${ }^{[21]}$ These e-ICUs exist in the USA and help curb the shortage of skilled professionals by providing live skill support to ICU personnel in remote areas.

Findings from interviews conducted with junior participants revealed issues related to conflicts due to staff hierarchy and being heard and valued in the ICU. Traditional hierarchy of staff in an ICU setting was a common challenge for junior participants. Research has shown that when professionals high up in the hierarchy such as physicians engage in active listening and encourage other professionals to share their ideas, inter-professional communication among team members improved dramatically. ${ }^{[22]}$ The use of communication checklists and tools is recommended because these tools reduce errors and omissions of critical and relevant patient-related information during patient handover. ${ }^{[23]}$

Both junior and senior participants agreed that there are differing views of what is 'teamwork' among the different healthcare professions. Evidence shows that teamwork can be enhanced between inter-professional team members by using inter-professional education training programmes where undergraduate students are trained through simulation of patient cases to collaboratively assess, treat and problem solve. ${ }^{[24]}$

One of the limitations of the present study was that it was conducted in an urban setting. The perception of physiotherapists working in ICUs in low-population, semi-urban areas may be different from those working in overloaded and demanding environments. There is a possibility that researchers may have allowed their prior experiences working as physiotherapists in the ICU to influence the interviewing process to focus on aspects that personally resonated with them. Olson ${ }^{[2]}$ felt that it could be difficult for the interviewer to step back and be objective. The study focused on the physiotherapists' perceptions of inter-professional team members which are based on events that may have occurred months before the interviews took place and may have been distorted. Direct observation of inter-professional team members interacting with physiotherapists would corroborate the findings of this study. Future studies could explore other members of the inter-professional ICU team's perceptions of interactions with physiotherapists. This could assist in the identification of key factors that influence the inter-professional team interactions in ICU, and solutions to barriers to inter-professional team collaboration can be developed.

\section{Conclusion}

Physiotherapists are key role players in ICU early mobilisation and prevention of physical fitness decline post critical illness, and exploring their interactions with other team members has identified solutions that may improve collaboration among inter-professional team members. Being able to communicate with an ICU patient is equally as important as being able to communicate with other professionals in the ICU setting. $\mathrm{CPD}$ was identified as a possible solution to improve relational barriers and facilitate communication, professionalism, friendliness and respect among inter-professional team members in the ICU.

\section{Declaration. None.}

Acknowledgements. The authors would like to thank all the participants for availing themselves to participate in this study.

Author contributions. MNN and HvA conceptualised the study, analysed the data and wrote the manuscript. Both authors approved the manuscript for publication.

\section{Funding. None.}

Conflicts of interest. None.

1. Yeole UL, Chand AR, Nandi BB, Gawali PP, Adkitte RG. Physiotherapy practices in intensive care units across Maharashtra. Indian J Crit Care Med 2015;19(11):669-673. https://doi. org/10.4103/0972-5229.16934

2. Stollings JL, Devlin JW, Pun BT, et al. Implementing the ABCDEF bundle: Top 8 questions asked during the ICU liberation ABCDEF bundle improvement collaborative. Crit Care Nurse 2019;39(1):36-45. https://doi.org/10.4037/ccn2019981

3. Costa DK, White MR, Ginier E, et al. Identifying barriers to delivering the awakening and breathing coordination, delirium, and early exercise/mobility bundle to minimise adverse outcomes chest.2017.03.054

4. Stiller K. Physiotherapy in intensive care. Chest 2013;144(3):825-847. https://doi.org/10.1378/ chest.12-2930

5. Lord RK, Mayhew CR, Korupolu R, et al. ICU early physical rehabilitation programs. Crit Care Med 2013;41(3):717-724. https://doi.org/10.1097/ccm.0b013e3182711de2

6. Plani N, Becker P, van Aswegen $\mathrm{H}$. The use of a weaning and extubation protocol to facilitate effective weaning and extubation from mechanical ventilation in patients suffering from traumatic injuries: A non-randomised experimental trial comparing a prospective to retrospective cohort Physio Theory Prac 2012;29(3):211-221.

7. Hickmann CE, Castanares-Zapatero D, Bialais E, et al. Teamwork enables high level of early mobilisation in critically ill patients. Ann Intens Care 2016;6(1).80. https://doi.org/10.1186/s13613016-0184-y

8. Paganini MC, Bousso RS. Nurses' autonomy in end-of-life situations in intensive care units. Nursing Ethics 2014;22(7):803-814. https://doi.org/10.1177/0969733014547970

9. The TEAM study Investigators. Early mobilisation and recovery in mechanically ventilated patients in the ICU: A bi-national, multi-centre, prospective cohort study. Critical Care 2015;19(1):81. https:/doi.org/10.1186/s13054-015-0765-4

10. O'Neill CS, Yaqoob M, Faraj S, O'Neill CL. Nurses' care practices at the end of life in intensive care units in Bahrain. Nurs Ethics 2016;22;24(8):950-961. https://doi.org/10.1177/0969733016629771

11. McAndrew NS, Leske JS. A balancing act. Clin Nurs Res 2014;25;24(4):357-374. https://doi org/10.1177/1054773814533791

12. Thomas P, Paratz J, Lipman J. Seated and semi-recumbent positioning of the ventilated intensive care patient - effect on gas exchange, respiratory mechanics and hemodynamics. Heart Lung 2014;43(2):105-111. https://doi.org/10.1016/j.hrtlng.2013.11.011

13. Coscia A, Bertino E, Tonetto P, et al. Communicative strategies in the neonatal intensive care unit. J Matern Fetal Neon Med 2010;23(3):11-23. https://doi.org/10.1186/s12937-017-0308-8

14. Ersson A, Beckman A, Jarl J, Borell J. Effects of a multifaceted intervention QI program to improve . Ersson A, Beckman A, Jarl J, Borell J. Effects of a multifaceted intervention QI program to improve
ICU performance BMC Health Serv Res 2018;18:838. https://doi.org/10.1186/s12913-018-3648-y

15. Centofanti JE, Duan EH, Hoad NC, et al. Use of a daily goals checklist for morning ICU rounds: A mixed-methods study. J Crit Care Med 2014;42:1797-1803 https://doi.org/10.1097/ CCM. 0000000000000331

16. Gupte P, Swaminathan N. Nurse's perceptions of physiotherapists in critical care team: Report of a qualitative study. Indian J Crit Care Med 2016;20:141-145. https://doi. org/10.4103\%2F0972-5229.178176

17. Moss M, Nordon-Craft A, Malone D, et al. A randomised trial of an intensive physical therapy program for patients with acute respiratory failure. Am J Respir Crit Care Med 2016;193(10):11011110. https://doi.org/10.1164\%2Frccm.201505-1039oc

18. Shoorideh FA, Ashktorab T, Yaghmaei F, Alavi Majd H. Relationship between ICU nurses' moral distress with burnout and anticipated turnover. Nurs Ethics 2015;22(1):64-76. https://doi. moral distress with burnout and

19. Fiabane E, Giorgi I, Sguazzin C, et al. Work engagement and occupational stress in nurses and other healthcare workers: The role of organisational and personal factors. J Clin Nurs 2013;22(1718):2614-2624.https://doi.org/10.1111/jocn.12084

20. Assimacopoulos, A, Alam, R, Arbo, M, et al. A brief retrospective review of medical records comparing outcomes for in-patients treated via telehealth versus in-person protocols: Is telehealth equally effective as in-person visits for treating neutropenic fever, bacterial pneumonia, and infected bacterial wounds. Telemed J E-Health 2008;14:762-768. https://doi.org/10.1089/tmj.2007.0128.

21. Nesher L, Jotkowitz A, Ethical issues in the development of tele-ICUs. J Med Ethics 2010;11(37):655657. https://doi.org/10.1136/ime.2010.040311

22. Laerkner E, Egerod I, Hansen HP. Nurses' experiences of caring for critically ill, non-sedated, mechanically ventilated patients in the intensive care unit: A qualitative study. Intens Crit Care Nurs 2015;31:196-204. https://doi.org/10.1016/j.iccn.2015.01.005

23. De Meester K, Verspuy M, Monsieurs KG, et al. SBAR improves nurse-physician communication and reduces unexpected death: A pre and post intervention study. Resusc 2013;84(9):1192-1196. https://doi.org/10.1016\%2Fj.resuscitation.2013.03.016

24. Olson R, Bialocerkowski A. Interprofessional education in allied health: A systematic review. Med Edu 2014:48:236-246 https://doi.org/10.1111/medu.12290 